\title{
High-Efficiency Organogenesis and Evaluation of the Regenerated Plants by Flow Cytometry of a Broad Range of Saccharum Spp. Hybrids (Sugarcane)
}

\section{Gabriela Nogueira}

Universidade Federal de Lavras

Zanderluce Luis

Embrapa: Empresa Brasileira de Pesquisa Agropecuaria

Leila Salles

Universidade Federal de Lavras

Moacir Pasqual

Universidade Federal de Lavras

Jonny Scherwinski-Pereira ( $\sim$ jonnyscherwinski@gmail.com )

Embrapa Recursos Genéticos e Biotecnologia https://orcid.org/0000-0001-6271-332X

\section{Research Article}

Keywords: Saccharum sp, Large-scale propagation, Morphological variation, DNA content

Posted Date: June 4th, 2021

DOI: https://doi.org/10.21203/rs.3.rs-441463/v1

License: () (i) This work is licensed under a Creative Commons Attribution 4.0 International License. Read Full License 


\section{Abstract}

The aim of this study was to evaluate the organogenic potential of Brazilian sugarcane varieties, in addition to verifying the in vitro multiplication rate and genetic stability by flow cytometry over monthly and consecutive subcultures. Thus, stem apices of twenty-two varieties were collected in the field and taken to the laboratory where external layers of leaves were removed. After disinfection, the achlorophyllous portion was sectioned and placed on MS medium with $5.0 \mathrm{mg} \mathrm{L}^{-1} \mathrm{NAA}$ and $0.5 \mathrm{mg} \mathrm{L}^{-1} \mathrm{KIN}$. For multiplication rate assessments, ten varieties were selected and inoculated in of liquid or semi-solid MS medium with $0.10 \mathrm{mg} \mathrm{L}^{-1} \mathrm{KIN}$ and $0.20 \mathrm{mg} \mathrm{L}^{-1}$ BAP, and subcultured every 30 days for a period up to 8 months. Genetic stability was verified by flow cytometry every two subcultures. At the end of the experiment, sprouts were rooted and acclimatized in a greenhouse. Regeneration occurred both by direct and indirect organogenesis, and the sugarcane varieties differed significantly in their regeneration capacity and number of adventitious shoots formed. For multiplication, a significant interaction was observed between variety, consistency of the culture medium and number of subcultures. In general, in the first subcultures, the liquid medium gave similar or better results compared with semi-solid medium; however, from the fourth transplanting onward, the semi-solid medium was superior. Morphological variations were verified from the fourth subculture. In addition, in some varieties, small changes in the relative DNA content were detected by flow cytometry. Sprouts of normal-looking sugarcane were successfully rooted and acclimatized after the eighth subculture.

\section{Introduction}

Plant tissue culture has been effectively used for clonal propagation and genetic improvement of different crops (Rocha et al. 2012), providing more productive and pathogen resistant plants, with greater vigor and adaptability to different environments (Piperidis et al. 2010). However, availability of performant selection, regeneration and proliferation procedures is a prerequisite for this (Yang et al. 2010).

Since the first studies on the cultivation of sugarcane cells and tissues started in the 1960s, numerous techniques have been developed. Organogenic and embryogenic pathways have become widely used for regeneration (Lakshmanan et al. 2006), although the competence and determination of explants varied significantly between genotypes (Garcia et al. 2007; Basnayake et al. 2011; Nogueira et al. 2019). Currently, biotechnological methods are commonplace in sugarcane mass propagation agribusiness, yielding plants with better quality and faster than conventional methods (Snyman et al. 2011; Lal et al. 2014). However, some limitations include microbial contamination, phenolic oxidation, vitrification, added to stress of the in vitro environment that can induce genetic instability of materials (Wang and Wang, 2012; Lal et al. 2014).

The source of explants, the method of cultivation applied, the time and number of subcultures, as well as the concentration and type of growth regulators used, often influence the occurrence of somaclonal variations under in vitro conditions (Huang et al. 2012; Krishna et al. 2016). These variations can impact the morphological, physiological, biochemical and genetic/epigenetic traits (Kaeppler et al. 2000; Huang et al. 2012), and still remain one of the major problems of plant tissue culture (Bairu et al. 2011).

Recent research has shown that the early evaluation of the genetic stability of plants regenerated in vitro can be useful to prove the trueness-to-type of regenerants, especially during clonal micropropagation and in genetic transformation studies (Sengar at al. 2011; Pandey et al. 2012; Krishna et al.

2016). Among the various techniques available, special attention has been given to flow cytometry (Mallón et al. 2010; Prado et al. 2010), as the particles are analyzed individually and at high speed, and large populations of cells can be measured in a short time (Shapiro, 2004). Flow cytometry has therefore become an excellent method for screening ploidy, detecting mixoploidy and aneuploidy, and estimating the total DNA content (Dolezel and Bartos 2005; Pasqual et al. 2012; Nogueira et al. 2015).

In Brazil, despite the economic importance of sugarcane and the cultivation of plantlets on a large scale via tissue culture, no major study had been carried out to date to identify the most responsive Brazilian varieties in vitro and, mainly, to verify their behavior and cytogenetic stability under prolonged culture.

This work aimed to evaluate the organogenic potential and in vitro multiplication rate of Brazilian sugarcane varieties, as well as to determine by flow cytometry the average nuclear DNA content of the regenerants over eight consecutive subcultures.

\section{Material And Methods Organogenic potential of Brazilian sugarcane varieties}

To verify the organogenic potential of sugarcane plants, stem tips of twenty-two Brazilian varieties were collected at Embrapa Tabuleiros Costeiros, Rio Largo - AL and sent to the Embrapa Genetic Resources and Biotechnology II Tissue Culture Laboratory, Brasília, DF, Brazil.

In the laboratory, the stem tips were washed with detergent in running water and the outer layers of leaves removed, to facilitate handling in the laminar flow chamber and avoid contamination of explants in vitro. After the initial cleaning, the apices were immersed in $70 \%$ alcohol for 1 minute, sodium hypochlorite ( $\mathrm{NaClO}$ ) (2.5\% active chlorine) for 20 minutes, followed by three washes in distilled autoclaved water. With the aid of tweezers and scalpel, about 2 to 3 leaves were removed and the innermost and achlorophyllous portion was sectioned transversely (ca. $3 \mathrm{~mm}$ thick). To avoid oxidation, explants were quickly inoculated into a culture medium containing MS salts (Murashige and Skoog, 1962), supplemented with $30 \mathrm{~g} \mathrm{~L}^{-1}$ sucrose, 5.0 
$\mathrm{mg} \mathrm{L}^{-1}$ naphthalenoacetic acid (NAA), $0.5 \mathrm{mg} \mathrm{L}^{-1}$ kinetin (KIN) and solidified with $2.3 \mathrm{~g} \mathrm{~L}^{-1}$ Phytagel $($ (Sigma, St. Louis, MO, USA), according to the protocol by Gill et al. (2006). The $\mathrm{pH}$ of the medium was adjusted to $5.8 \pm 0.1$ before autoclaving at $121^{\circ} \mathrm{C}$ and 1.5 atm for 20 minutes.

After inoculation, explants were maintained at $25 \pm 2{ }^{\circ} \mathrm{C}$, under a 16 hours light of photoperiod, with an irradiation of $30 \mu \mathrm{mol} . \mathrm{m}^{-2} . \mathrm{s}^{-1}$, provided by cold white fluorescent lamps (Sylvania, 40w).

Two stem tips were used for each variety of sugarcane, which were sectioned providing 30 explants that were distributed in a completely randomized design in 10 sterile Petri dishes $(15 \times 90 \mathrm{~mm})$, each containing three explant sections.

After 40 days of cultivation the percentage of regeneration, the average number of regenerated shoots, the percentage of formation of adventitious roots and calluses at the explant base, as well as the percentage of phenolic oxidation of explants were evaluated.

\section{Histological analysis}

For anatomical analysis and elucidation of the regeneration route from stem tips in vitro, samples were collected at 40 days of subculture and fixed in FAA 70 (Formaldehyde, acetic acid and 70\% ethanol, in a ratio of 1:1:18 v/v) (Johansen, 1940).

Subsequently, the samples were dehydrated in an increasing alcoholic series (70-100\%), infiltrated and included in historesin (Leica, Heidelberg, Germany) according to the manufacturer's recommendations. Transverse and longitudinal serial sections (7-10 $\mu \mathrm{m})$ were obtained in a manual rotary microtome (Leica model RM 2125), extended, and adhered to microscopic slides in a plate heated to $\pm 40^{\circ} \mathrm{C}$.

The sections were stained with Toluidine blue (O'Brien et al. 1964), followed by assembly between slide-coverslips with Entellan. The results were recorded in a light microscope, coupled to a digital image capture system (Software ImagePro 4.0).

\section{In vitro multiplication rate}

To evaluate the multiplication rate over consecutive subcultures, ten varieties of sugarcane regenerated via organogenesis were used as explant sources - SP716949; SP784764; SP701143; SP854594; RB83160; RB845210; RB863129; VAT90-212; VAT90-186; VAT90-61.

Sprouts were excised from the matrix in a laminar flow chamber, and inoculated in MS medium added with $30 \mathrm{~g} \mathrm{~L}^{-1} \mathrm{sucrose} 0.10 \mathrm{mg} \mathrm{L}-1$ kinetin (KIN) and $0.20 \mathrm{mg} \mathrm{L}^{-1}$ 6-benzylaminopurine (BAP). Semi-solid (SSM; $2.3 \mathrm{~g} \mathrm{~L}^{-1}$ of Phytagel) and stationary liquid (LM) media were compared. All explants were kept in a growth room under light conditions, where the cultivation conditions were the same for all varieties.

Subcultures were carried out every 30 days and, at the end of each one, in addition to the evaluation of the multiplication rate (number of shoots larger than $0.5 \mathrm{~cm}$ ), the height of the largest shoot until the intersection of the last leaf, the formation of rosettes and abnormalities, and the contamination of the culture medium were also determined. In total, 8 consecutive subcultures were carried out.

Each replicate included three $250 \mathrm{~mL}$ glass vials with 5 sprouts each for both SSM and LM media.

\section{Genetic stability assessments through flow cytometry}

Every two subcultures, newly formed sprouts of the ten varieties were collected and evaluated for the average content of nuclear DNA by flow cytometry, at the Tissue Culture Laboratory - Department of Agriculture at the Federal University of Lavras (Laboratório de Cultura de Tecidos Departamento de Agricultura da Universidade Federal de Lavras), Lavras - MG.

Approximately 20-30 mg of young leaves of the plants and the internal reference standard - tomato (Lycopersicum esculentum L.) were used. The tissues were ground in a Petri dish containing $1 \mathrm{~mL}$ of cooled extraction buffer to release the nuclei. The nucleus extraction buffer used contained 50 $\mathrm{mM}$ glucose, $15 \mathrm{mM} \mathrm{NaCl}, 15 \mathrm{mM} \mathrm{KCl}, 5 \mathrm{mM} \mathrm{Na}_{2}$.EDTA, $50 \mathrm{mM}$ sodium citrate, 0.5\% Tween 20, $50 \mathrm{mM} \mathrm{HEPES} \mathrm{(pH} \mathrm{7.2)} \mathrm{and} \mathrm{1 \%} \mathrm{(m/v)}$ polyvinylpyrrolidone-10 (PVP-10), as reported by Marie and Brown (1993). After extraction the nuclei suspension was filtered through a 50 mm mesh, and nuclei were stained by adding $25 \mu \mathrm{L}$ of a solution of $1 \mathrm{mg} / 1 \mathrm{~mL}$ of Propidium lodide.

The nuclear DNA content of the plants in $(\mathrm{pg})$ was estimated using the formula: Sample DNA = (G1 of the sample/G1 of the standard) $\times$ DNA of the standard.

The analyzes were performed using a FacsCalibur cytometer (BD, Biosciences, San Jose, CA, USA) and the histograms generated were analyzed using the WinMDI 2.8 software. The design was completely randomized with 4 replications per variety, each composed of a sprout and two readings.

\section{In vitro rooting and acclimatization in a greenhouse}

At the end of the eighth subculture, sprouts were individualized, transferred to rooting medium, and rooted plants were acclimatized in a greenhouse.

Roots were induced on half-strength MS medium plus $5.0 \mathrm{mg} \mathrm{L}^{-1} \mathrm{NAA}$ (Pathak et al. 2009), $30 \mathrm{~g} \mathrm{~L}^{-1}$ sucrose and $2.3 \mathrm{~g} \mathrm{~L}^{-1} \mathrm{Phytagel}$. The pH was adjusted to $5.8 \pm 0.1$ and the medium, distributed in test tubes $(25 \times 150 \mathrm{~mm})$ before autoclaving for 20 minutes. 
For each variety, sprouts were transferred under a laminar flow hood and labeled according to the multiplication medium (LM or SSM), with ten sprouts from LM medium and ten from SSM medium, and were kept in a growth room under the same light and temperature laboratorial conditions previously described.

Root induction, the height of sprouts $(\mathrm{cm})$ and the formation of secondary shoots were evaluated on the 40th day of cultivation and, shortly thereafter pre-acclimatization of explants started, still in the growth room by initially removing the PVC film used to seal the test tubes and, 72 hours later, the tube caps also. After 48 hours without any kind of sealing, the sprouts were washed in running water, to remove residues from the culture medium, and taken to a greenhouse where they were transplanted in Bioplant substrate (Nova Ponte, Minas Gerais, Brazil) and sand, in a 1:1 (v/v) ratio.

To provide a moist microclimate for the sprouts during acclimatization, they were covered by a plastic cover and irrigated daily for a period of seven days. After 21 days of acclimatization, the percentage of survival, the number of shoots and the height of the aerial part (cm) were recorded.

\section{Statistical analysis}

All data obtained were subjected to analysis of variance, using the statistical program Sisvar (Ferreira, 2011) and the means were compared by the Scott-Knott test at $5 \%$ probability. Those data expressed as a percentage were transformed by arc sine $(x / 100)^{1 / 2}$.

\section{Results And Discussion}

Organogenic potential of sugarcane varieties and histological analysis

The regeneration of sugarcane in vitro from immature leaf segments was fast and efficient, and a large number of shoots were obtained in a short time.

According to Gill et al. (2006), the regeneration method applied is simple and easily reproducible for inducing direct plant regeneration from immature leaf segments. However, contrary to their results, the regeneration of the Brazilian sugarcane varieties studied in this work occurred both by the direct (Fig. 1A) and indirect organogenic pathways (Fig. 1C), the latter with callus formation at the base of the explants.

Histological analyses confirmed the development of adventitious buds containing apical meristem and leaf primordia formed directly from the leaf explant, in addition to the development of the procambium connecting the buds with the source explant (Fig. 1B). Adventitious buds also developed from nodular calluses formed at the base of the original explants. Fig. 1D shows an adventitious bud in early development, containing apical meristem, leaf primordial and procambial tissues. These features showed the unipolar structure of buds, with a wide connection with the organogenic callus. At a more advanced stage adventitious buds containing vascular bundles already developed were observed (Fig. 1E).

In general, the organogenic process for all varieties we studied occurred asynchronously, with the presence of buds and shoots at different stages of development. Garcia et al. (2007) found that in vitro sugarcane plants incubated in light and in the presence of a high concentration of auxin exhibited direct regeneration from the outer layer of the fundamental parenchyma first, followed by the development of organogenic calluses. Dibax et al. (2013) in turn, verified the regeneration of shoots of two varieties of sugarcane (RB92579 and RB93509) from two different types of tissues: nodular calluses similar to globular somatic embryos in a stage or translucent organogenic calluses with intense cell division.

In this study, the calluses formed at the base of the explants were initially friable and had a mucilaginous aspect. Subsequently, on this tissue, a whitish-colored nodular compact callus emerged. Within approximately 15 days of cultivation there was a proliferation of callogenic masses and the development of buds and adventitious shoots, evidenced by the green color.

Table 1 details the percentage of calluses formed at the base of the explants for each variety studied, in addition to characteristics such as percentage of adventitious root formation and phenolic oxidation.

Regarding the percentage of regeneration, among the twenty-two varieties studied, seven of them (SP784764, SP854594, RB845210, VAT90-186, VAT90-212, SP716949 and RB99395) were more responsive to the treatment used compared to the others and showed an average regeneration rate of at least $81.9 \%$ (Fig. 2A).

A group of nine varieties showed an intermediate regeneration rate, of around $60 \%$. The varieties with the lowest frequency of regeneration, in turn, were: SP813804 (16\%), RB93509 (14.1\%), RB92579 (14.1\%), CB98710 (14.6\%), RB951541 (12\%) and RB867515, where only 4.11\% of explants were organogenic.

Lakshmanan et al. (2006) suggested that although genotypes play an important role in controlling shoot regeneration in vitro, this effect can be minimized with the concentration and type of auxin used, the polarity and orientation of the tissue, as well as the size and stage of development of explants. In this context, the need to adapt the protocol used for less responsive varieties becomes evident.

In addition to the variation in the percentage of regeneration, the varieties also differed significantly in terms of the number of adventitious shoots formed. With significantly higher results, the VAT90-186, VAT90-212 and SP716949 varieties stood out with an average formation of 35.3 ; 29.8 and 43.5 shoots per glass vial, respectively (Fig. 2B).

Page $4 / 15$ 
It thus appeared that the varieties most responsive to regeneration (SP854594, RB845210, VAT90-186, VAT90-212 and SP716949) were also those with the highest percentage of explants with callus formation on the cut surface and adventitious roots, and yet, with the lowest percentage of oxidation. On the contrary, the varieties with the lowest percentage of regeneration (RB951541; RB93509; RB92579 and SP813804) also exhibited the highest rate of oxidated explants, which certainly compromised their regeneration (Table 1 and Fig. 2).

\section{In vitro multiplication rate}

According to the statistical analysis, the results found for the average number of shoots and height of the highest sprout showed a significant interaction between variety, consistency of the culture medium and number of subcultures.

The varieties behaved differently in terms of the potential for multiplication of shoots within and between the culture media used. In general, in the first subcultures the liquid medium (LM) gave similar or superior results compared with the semi-solid medium (SSM). However, as of the fourth subculture, SSM was the one with the highest multiplication rate for all varieties analyzed (Fig. 3).

Variety SP701143 showed the highest average shoot formation along subcultures on both culture media compared with the other varieties. A significant increase in the number of shoots was seen with time in culture, reaching an average of 11.2 shoots/tiller in SSM and 6.9 shoots/tiller in LM in the last three subcultures (Fig. 3). This high multiplication rate can be explained by the large number of shoots formed at the base of a main tiller, often smaller than $1.0 \mathrm{~cm}$ in height.

The varieties RB83160, RB845210 and SP716949 showed a similar multiplication rate, with an increase with time in the production of shoots on SSM medium, but maintaining a constant rate on LM throughout cultivation time. The height of shoots in LM was of approximately $3.4 \mathrm{~cm}$ for all three varieties, whereas in SSM shoots of the variety SP716949 were significantly higher, with average $3.7 \mathrm{~cm}$ vs. $2.8 \mathrm{~cm}$ for the others. It was also observed that the increase in the number of sprouts for variety RB845210 occurred at the expense of their growth.

The varieties VAT90-61, RB863129 and SP784764 showed no production of multiple shoots during the experiment. The varieties VAT90-212 and SP854594, in turn, had a good multiplication rate and, like the other varieties, SSM medium yielded the best results, after the fourth subculture (Fig. 3). Shoot sizes remained close to $3.0 \mathrm{~cm}$.

The potential for sugarcane multiplication is highly influenced by the genotype (Cheema e Hussain, 2004; Cidade et al. 2006; Ali et al. 2008; Khan et al. 2008; Vieira et al. 2009), which explains the wide variation in cultivation conditions found in sugarcane work, especially with regard to the concentration and type of growth regulators (Biradar et al. 2009; Khan et al. 2009; Uzma et al. 2012; Rocha et al. 2013). In most cases, the hormonal interaction between the cytokinins BAP and KIN was proven more efficient in the development of multiple shoots (Khan et al. 2009; Vieira et al. 2009).

To date, no reports have been found regarding the potential for multiplication of the Brazilian sugarcane varieties studied in this work. From our results, the superiority of the semi-solid culture medium for production of multiple shoots in the last subcultures can be explained by an onset of bacterial contamination in the liquid medium and by the morphological variation of sprouts formed from the fourth subculture. In this respect, despite the ease of work and good multiplication rate, in the liquid medium there was a progression in contaminations, reaching a peak of approximately $45 \%$ by the end of the eighth subculture. This had negative effects on sugarcane multiplication, which was even completely inhibited for some varieties, such as with VAT90-186 variety. The percentage of contamination in the SSM medium was significantly lower, with an average of $10 \%$ at the end of the experiment.

Morphological variations were also observed over consecutive subcultures. From the fourth transplanting, a larger formation of small shoots ( $<1.0 \mathrm{~cm})$ was observed at the base of a larger main sprout. This type of arrangement was called rosette in this study (Fig. 4A).

The rate of rosette formation was significantly higher when the tillers were grown on a semi-solid medium and was highly influenced by the genotype. The most pronounced levels of rosette formation were observed in varieties RB845210 and SP701143, reaching 37 and $34 \%$, respectively, followed by the variety SP716949, with an average of 19\% rosette formation in SSM medium. The other varieties presented this type of disposition less frequently, at rates that varied up to $10 \%$ during subcultures, regardless of the type of culture medium used.

The arrangement of the shoots and the phenotypic variations observed over time have practical implications on the large-scale production of healthy and uniform plantlets, as the individualization of the tillers and the rooting process can be compromised. Generally, this shortening is reversible when the shoots are transferred to basal media without growth regulators, particularly cytokinins, before the rooting phase (Scherwinski-Pereira et al. 2012). The addition of exogenous cytokinins in the culture medium is often required for the differentiation and formation of adventitious shoots, but they may induce morphological abnormalities. Ramage and Willians (2004) verified the formation of rosettes in tobacco plants grown in presence of BAP. Vitrified shoots (Sivanesan e Jeong, 2012), anatomical and ultrastructural variations (Quiala et al. 2012), stunting and excessive branching (Honda et al. 2011) were also detected as typical changes caused by cytokinin.

In this research, eventually, the appearance of green masses was observed, characterized by the excessive formation of small and apparently abnormal sprouts with twisted, disorganized leaves and a light green color (Fig. 4B). These were observed during the multiplication of RB845210 variety from the fifth subcultivation. In addition, in some cases isolated sprouts or at the base of the clumps were formed, showing oxidized and/or necrotic leaves (Fig. 4C). Probably, the excess of growth regulators, resulting from a carryover due to the numerous multiplication cycles, may have caused such variations. 
In vitro sugarcanes sometimes exhibited considerable levels of somaclonal variation (Larkin and Scowcroft, 1981; Zucchi et al. 2002). Taylor et al. (1995) found morphological variations such as abundant tillering and leaf blade folding in sugarcane plants regenerated from embryogenic calluses, although molecular analyses detected few polymorphic bands indicating that genetic variations were uncommon. However, genetic variations have been reported previously for the species and, in general, should be considered. Heinz and Mee (1971) working with sugarcane plants (variety H50-7209) regenerated from callus culture, detected clones with variations in the chromosome number, of 94 to 120 . Genetic variations between regenerators of distinct morphogenic routes (direct and indirect) have been reported by Suprasanna et al. (2010). In general, these studies have shown that some sugarcane genotypes are more prone to variation than others and that instability is possibly a consequence of the interaction between genotype and culture medium (Zucchi et al. 2002; Snyman et al. 2011). This fact is also proven through our results here, where the ten Brazilian varieties of sugarcane studied showed different levels of phenotypic variation when grown under the same environmental conditions.

Variations at different levels have also been found for other species in the Poaceae family. Chromosomal aberrations, variations in the DNA nucleotide sequence (insertions and deletions), as well as morphological variations have already been detected in rice (Oryza spp.) regenerated in vitro (Kharabian e Darabi, 2005; Rasheed et al. 2005; Miyao et al. 2012). Similarly, variations in barley plants have also been reported (Bednarek et al. 2007). Some authors believe that somaclonal variation is an alternative way of creating variants and thus expanding the variability of the species germplasm (Li etal., 2010). However, it is undesirable in the clonal multiplication of genetically uniform plantlets for commercial purposes.

\section{Genetic stability assessments through flow cytometry}

Sugarcane has proved to be an excellent candidate for studies of somaclonal variation, due to a combination of factors such as in vitro efficiency, morphological variations, genomic complexity and economic importance. In general, the analysis of in vitro sprouts by flow cytometry resulted in a G1 peak of DNA with good resolution and coefficients of variation below 3.5\%. Representative histograms of three varieties of sugarcane are shown in Fig 5 .

Of the ten varieties studied, seven (RB83160, VAT90-186, VAT90-212, SP701143, SP854594, RB845210 and SP716949) showed no variation in the relative nuclear DNA content over eight successive subcultures. However, for varieties RB863129, VAT90-61 and SP784764, statistical differences were detected in this trait (Table 2).

The varieties RB863129 and SP784764 showed a reduction of approximately 0.45 pg DNA, starting from the fourth subculture. In contrast, the VAT9061 variety exhibited an increasing trend in relative DNA content over time in vitro.

Variations in the relative amount of DNA, even if small, occurred in $30 \%$ of the varieties from the fourth subculture and coincided with the appearance of morphological changes in the explants. These two characteristics underline the need to control the number of consecutive subcultures for sugarcane. The size of the plant genome or the $2 \mathrm{C}$ nuclear DNA content is highly plastic in response to environmental conditions (Msogoya et al. 2011). According to Bennetzen et al. (2005), the increase in the genome size may be caused by phenomena such as polyploidy and by transposable elements (transposons). On the contrary, the decrease frequently occurs due to deletions or chromosomal breaks (Petrov 2001).

In vitro, the stress caused by constant transplanting, the use of growth regulators and the cultivation for a prolonged period may have contributed to the occurrence of these phenomena, since, in three varieties (RB863129, SP784764 and VAT90-61) genomic instability was observed (Table 2).

Previously, Nogueira et al. (2015) found that the storage of sugarcane genotypes for long periods in vitro, even under conditions of minimal growth, can lead to changes in the estimated amount of nuclear DNA and, thus, increase the risk of somaclonal variations.

It should also be noted that variations in the global DNA content in response to in vitro culture were also detected by flow cytometry for other plant species. The combination of 2,4-D with kinetin caused a reduction in the relative amount of DNA, corresponding to the loss of 4 to 5 chromosomes, in some Gossypium hirsutum plants regenerated by callus culture (Jin et al. 2008).

Banana micropropagation resulted in the formation of somaclones with significantly lower leaf DNA content (1.72 picograms) when compared to normal plants, with an estimated value of 1.82 picograms. It is noteworthy that these plants were detected in field condition for presenting morphological variations (Msogoya et al. 2011). However, Loureiro et al. (2007) showed that morphological variations are not always directly associated with genetic changes, as Juniperusphoenicea plants micropropagated in vitro, although presenting different morphotypes, did not differ in the amount of DNA.

Given the above, flow cytometry analysis demonstrates the potential to quickly detect the genomic instability of materials grown in vitro and suggest further studies, when necessary.

\section{In vitro rooting and acclimatization in a greenhouse}

The rooting process of sugarcane sprouts from in vitro multiplication occurred efficiently, as can be seen in Table 3 . Plants from the liquid medium showed a rate of 90 to $100 \%$ rooting, except for the variety RB845210, which had significantly lower root formation (60\%). It should be noted that, among the varieties studied, four did not have enough plants to be rooted and then acclimatized.

On the other hand, there was no significant difference in the rooting of sprouts from the semi-solid medium between the 10 varieties evaluated. Root proliferation in vitro occurred between 80 and $100 \%$ of sprouts (Table 3 ). The average number of roots formed was high (above 20 per plant), but it 
varied between the varieties and their medium of origin. New shoots were also produced during rooting in vitro.

The root quality is essential for success in the acclimatization stage. In this work, the formation of vigorous roots and the presence of many root hairs were observed. There was no callus formation at the base of explants and adventitious roots were produced directly from the basal portion of plants (Fig. $6 \mathrm{~A}$ and $\mathrm{C}$ ).

The survival of shoots multiplied and rooted in vitro was greater than $80 \%$ when transplanted to substrate in the greenhouse. In general, all the plants that produced roots managed to establish themselves ex vitro, demonstrating the importance of this stage for completion of the micropropagation system of the species. Within three weeks in substrate, the plants adapted well to the external environment and showed a significant increase in the length of the aerial part for all the sugarcane varieties evaluated (Fig. $6 \mathrm{D}$ and E). As in the rhizogenesis phase, the source medium did not interfere with the development of plants in the greenhouse.

\section{Conclusions}

The regeneration of stem tips of Brazilian varieties of sugarcane occurs both directly and through an indirect path in a period of approximately 30 to 40 days. However, the organogenic potential is genotype dependent. Among twenty-two varieties studied, sixteen had a regeneration rate equal to or greater than $60 \%$ of the explants. In general, during the first subcultures the liquid medium multiplication results were similar or superior as compared to the semi-solid (SSM) and, from the fourth subculture, the SSM showed the highest multiplication rate for all the varieties analyzed. However, in vitro cultivation for a period of more than four transfers induced morphological variations and altered the relative content of nuclear DNA in sugarcane plants.

It can be therefore concluded that, despite the high rate of multiplication in vitro of the sugarcane varieties, the amount of variations observed after a certain number of subcultures can make the process of obtaining plantlets unfeasible clearly demonstrating a periodic need to renew the material to be propagated.

\section{Declarations}

\section{Acknowledgement}

The authors thank Dr. Adriane Amaral from Embrapa Tabuleiros Costeiros, Rio Largo, AL, Brazil, for sending the material for the experiments. This work was funded by Coordenação de Aperfeiçoamento de Pessoal de Nível Superior (Capes/Embrapa 001-2011/Grant 39) and Conselho Nacional de Desenvolvimento Científico e Tecnológico (CNPq 308731/2019-0).

\section{Author contributions}

GFN and JES-P performed and designed experiments, analyzed and interpreted data and wrote the manuscript. ZGL assisted in morpho-anatomical and histochemical analysis. LAS and MP assisted in Flux Cytometry data analysis and interpretation.

\section{References}

1. Ali A, Naz S, Eqbal J (2008) An efficient protocol for large scale production of sugarcane through micropropagation. Pakistan J Bot 40 : $139-149$

2. Andrade GRD (2011) Resposta do sistema antioxidativo sob a influência de 6-benzilaminopurina na micropropagação de cana-de-açúcar. 2011. 75 p. Dissertação (Mestrado em Química). Universidade Federal Rural de Pernambuco, Recife, 2011.

3. Bairu MW, Aremu AO, Van Staden J (2011) Somaclonal variation in plants: causes and detection methods. Plant Growth Reg 63: 147-173

4. Basnayake SWV, Moyle R, Birch RG (2011) Embryogenic callus proliferation and regeneration conditions for genetic transformation of diverse sugarcane cultivars. Plant Cell Rep 30: 439-448

5. Bednarek PT, Orlowska R, Koebner RMD, Zimny J (2007) Quantification of the tissue-culture induced variation in barley (Hordeum vulgare L.). BMC Plant Biology 7, 10. https://doi.org/10.1186/1471-2229-7-10

6. Bennetzen JL, Ma J, Devos KM (2005) Mechanisms of recent genome size variation in flowering plants. Ann Bot 95: 127-132

7. Biradar S, Biradar DP, Patil VC, Patil S, Kambar NS (2009) In vitro plant regeneration using shoot tip culture in commercial cultivar of sugarcane. Karnataka J Agricult Scienc 22: 21-24

8. Cheema KL, Hussain M (2004) Micropropagation of sugarcane through apical bud and axillary bud. Int J Agric Biol 6: 257-259

9. Cidade DAP, Garcia RO, Duarte AC, Sachetto-Martins G, Mansur E (2006) In vitro morphogenesis of Brazilian sugarcane varieties. Pesq Agrop Bras 41: 385-391

10. Dibax R, Alcantara GB, Machado MP, Bespalhok JV, Oliveira RA (2013) Protocol optimization and histological analysis of in vitro plant regeneration of RB 92579 and RB 93509 sugarcane cultivars. Cienc Rural 43: 49-54

11. Dolezel J, Bartos J (2005) Plant DNA flow cytometry and estimation of nuclear genome size. Ann Bot 95: 99-110

12. Ferreira DF (2011) SISVAR: a computer statistical analysis system. Cienc Agrotecnol 35: 1039-1042

Page $7 / 15$ 
13. Garcia R., Cidade D, Castellar A, Lips A, Magioli C, Callado C, Mansur E (2007) In vitro morphogenesis patterns from shoot apices of sugarcane are determined by light and type of growth regulator. Plant Cell Tiss Organ Cult 90: 181-190

14. Gill R, Malhotra PK, Gosal SS (2006) Direct plant regeneration from cultured young leaf segments of sugarcane. Plant Cell Tiss Organ Cult 84: 227231

15. Heinz DJ, Mee GWP (1971) Morphologic, cytogenetic, and enzymatic variation in Saccharum species hybrid clones derived from callus tissue. Am J Bot 58: 257

16. Honda C, Kusaba S, Nishijima T, Moriguchi T (2011) Transformation of kiwi fruit using the IPT gene alters tree architecture. Plant Cell Tiss Organ Cult 107: 45-53

17. Huang H, Han SS, Wang Y, Zhang XZ, Han ZH (2012) Variations in leaf morphology and DNA methylation following in vitro culture of Malus xiaojinensis. Plant Cell Tiss Organ Cult 111: 153-161

18. Jin S, Mushke R, Zhu H, Tu L, Lin Z, Zhang Y, Zhang X (2008) Detection of somaclonal variation of cotton (Gossypiumhirsutum) using cytogenetics, flow cytometry and molecular markers. Plant Cell Rep 27: 1303-1316

19. Johansen DA Plant microtechnique. New York: [s. n.], 1940. 523.

20. Kaeppler SM, Kaeppler HF, Rhee Y (2000) Epigenetic aspects of somaclonal variation in plants. Plant Mol Biol 43: 179-188

21. Khan SA, Rashid H, Chaudhary FM, Chaudhry Z, Afroz A (2008) Rapid micropropagation of three elite sugarcane (Saccharum officinarum L.) varieties by shoot tip culture. Afr J Biotechn 7: 2174-2180

22. Khan, S. A. et al. Effect of cytokinins on shoot multiplication in three elite sugarcane varieties. Pakistan J Bot 41: 1651-1658, 2009.

23. Kharabian A, Darabi A (2005) Characterization of some chromosomal aberrations in regenerated rice plants (Oryza sativa). Plant Cell Tiss Organ Cult 83: 161-168

24. Krishna H. et al. Somaclonal variations and their applications in horticultural crops improvement. Biotech, 6:54, 2016.

25. Lal M, Tiwari AK, Gupta GN, Kumari K (2014) Commercial Scale Micropropagation of Sugarcane: Constraints and Remedies. Sugar Tech 17: 339347

26. Lakshmanan P et al. (2006) Developmental and hormonal regulation of direct shoot organogenesis and somatic embryogenesis in sugarcane (Saccharum spp. interspecific hybrids) leaf culture. Plant Cell Rep 25: 1007-1015

27. Larkin PJ, Scowcroft WR (1981) Somaclonal variation - a novel source of variability from cell-cultures for plant improvement. Theor Appl Gen 60: 197-214

28. Li R, Bruneau AH, Qu R (2010) Tissue culture-induced morphological somaclonal variation in St. Augustinegrass Stenotaphrum secundatum (Walt.) Kuntze. Plant Breed 129: 96-99

29. Loureiro J. et al. (2007) Micropropagation of Juniperus phoenicea from adult plant explants and analysis of ploidy stability using flow cytometry. Biol Plant 51: 7-14

30. Mallón R, Rodriguez-Oubina J, Luz Gonzalez M (2010) In vitro propagation of the endangered plant Centaurea ultreiae: assessment of genetic stability by cytological studies, flow cytometry and RAPD analysis. Plant Cell Tiss Organ Cult 101: 31-39

31. Marie D, Brown SC (1993) A cytometric exercise in plant dna histograms, with 2C-values for 70 species. Biology of the Cell $78: 41-51$.

32. Miyao A. et al. (2012) Molecular spectrum of somaclonal variation in regenerated rice revealed by whole-genome sequencing. Plant Cell Physiol 53: 256-264

33. Msogoya TJ, Grout BW, Roberts A (2011) Reduction in genome size and DNA methylation alters plant and fruit development in tissue culture induced off-type banana (Musa spp.). J Animal Plant Sciences 11: 1450-1456

34. Murashige T, Skoog FA (1962) A revised medium for rapid growth and bioassays with tobacco tissue cultures. Physiol Plant 15: $473-497$

35. Nogueira GF et al. (2015) An approach on the in vitro maintenance of sugarcane with views for conservation and monitoring of plant nuclear DNA contents via flow cytometry. In Vitro Cell Dev Biol Plant 51: 220-230

36. Nogueira GF, Luis ZG, Pasqual M, Scherwinski-Pereira JE (2019) High-efficiency somatic embryogenesis of a broad range of Brazilian Saccharum spp. hybrids (sugarcane) varieties using explants from previously established in vitro plants. In Vitro Cell Dev Biol Plant 55:26-35

37. O'brien TP, Feder N, Mccully ME (1964) Polychromatic staining of plant cell walls by toluidine blue o. Protoplasma 59: 368

38. Pandey, R. N. et al. (2012) Early assessment of genetic fidelity in sugarcane (Saccharum officinarum) plantlets regenerated through direct organogenesis with RAPD and SSR markers. Australian J Crop Science 6: 618-624

39. Pasqual M, Pio LAS, Oliveira ACO, Soares JDR (2012). Flow Cytometry Applied. In: Leva, A and Rinaldi, L. M. R. (Ed.). Recent Advances in Plant in vitro Culture: InTech, 2012. 14p.

40. Pathak, S. et al. (2019) Effect of growth regulators on in vitro multiplication and rooting of shoot cultures in sugarcane. Sugar Tech 11: 86-88

41. Petrov DA (2001) Evolution of genome size: new approaches to an old problem. Trends in Genetics 17: 23-28.

42. Piperidis G, Piperidis N, D'hont A (2010) Molecular cytogenetic investigation of chromosome composition and transmission in sugarcane. Mol Gen Gen 284: 65-73 
43. Prado MJ et al. (2010) Detection of somaclonal variants in somatic embryogenesis-regenerated plants of Vitis vinifera by flow cytometry and microsatellite markers. Plant Cell Tiss Organ Cult 103: 49-59

44. Quiala E et al. (2012) Morphological and physiological responses of proliferating shoots of teak to temporary immersion and BA treatments. Plant Cell Tiss Organ Cult 109: 223-234

45. Ramage CM, Williams RR (2004) Cytokinin-induced abnormal shoot organogenesis is associated with elevated Knotted1-type homeobox gene expression in tobacco. Plant Cell Rep 22: 919-924

46. Rasheed S. et al. (2005) RAPD characterization of somaclonal variation in indica basmati rice. Pakistan J Bot 37: 249-262

47. Rocha DI et al. (2012) Anatomical and ultrastructural analyses of in vitro organogenesis from root explants of commercial passion fruit (Passiflora edulis Sims). Plant Cell Tiss Organ Cult 111: 69-78

48. Rocha PSG et al. (2013) Sugarcane micropropagation using light emitting diodes and adjustment in growth-medium sucrose concentration. Cienc Rural 43: 1168-1173

49. Scherwinski-Pereira JE, Lima ECA, Silva TL, Mesquita AGG, Maciel SA, Costa FHS (2012) Double-phase culture system for large scale production of pineapple. Plant Cell Tiss Organ Cult 109: 263-269

50. Sengar RS, Sengar K, Garg SK (2011) Biotechnological approaches for high sugarcane yield. Plant Sciences Feed, 1: 101-111

51. Shapiro HM (2004) The evolution of cytometers. Cytometry Part A 58A: $13-20$

52. Snyman SJ et al. (2011) Applications of in vitro culture systems for commercial sugarcane production and improvement In Vitro Cell Dev Biol Plant 47: 234-249

53. Sivanesan I, Jeong BR (2012) Identification of somaclonal variants in proliferating shoot cultures of Senecio cruentus cv. Tokyo Daruma. Plant Cell Tiss Organ Cult 111: 247-253

54. Suprasanna P et al. (2010) Profiling of culture-induced variation in sugarcane plants regenerated via direct and indirect somatic embryogenesis by using transposon- insertion polymorphism. Sugar Tech 12: 26-30

55. Taylor PWJ et al. (1995) Sensitivity of random amplified polymorphic DNA analysis to detect genetic change in sugarcane during tissue culture. Theor Appl Gen 90: 1169-1173

56. Uzma et al. (2012) Rapid in vitro Multiplication of Sugarcane Elite Genotypes and Detection of Sugarcane Mosaic Virus through Two Steps RTPCR. Intern J Agric Biol 14: 870-878

57. Vieira RA et al. (2009) Diferentes concentrações de 6-benzilaminopurina e cinetina na micropropagação in vitro das variedades RB 867515 e RB 855156 de cana-de-açúcar. Campo Digital 1: 122-126

58. Wang QM, Wang L (2012) An evolutionary view of plant tissue culture: somaclonal variation and selection. Plant Cell Rep 31: $1535-1547$

59. Yang JL et al. (2010) Direct somatic embryogenesis from pericycle cells of broccoli (Brassica oleracea L. var. italica) root explants. Plant Cell Tiss Organ Cult 100: 49-58

60. Zucchi MI et al. (2002) Genetic instability of sugarcane plants derived from meristem cultures. Gen Mol Biol 25: 91-95

\section{Tables}

Table 1 Percentage of sugarcane explants that presented callus at the base of the explants, formation of adventitious roots and phenolic oxidation during cultivation in MS culture medium plus $5.0 \mathrm{mg} \mathrm{L}^{-1}$ of NAA and $0.5 \mathrm{mg} \mathrm{L}^{-1}$ of KIN. 


\begin{tabular}{|llll|}
\hline Variety & Callus (\%) & Oxidation (\%) & Adventitious roots (\%) \\
\hline RB867515 & $4.1 \mathrm{c}$ & $20.6 \mathrm{c}$ & $37.2 \mathrm{a}$ \\
\hline RB951541 & $4.1 \mathrm{c}$ & $62.0 \mathrm{a}$ & $4.7 \mathrm{~b}$ \\
\hline RB93509 & 0.0 c & $61.5 \mathrm{a}$ & $4.6 \mathrm{~b}$ \\
\hline RB92579 & $14.0 \mathrm{c}$ & $66.5 \mathrm{a}$ & $4.7 \mathrm{~b}$ \\
\hline CB98710 & $22.1 \mathrm{c}$ & $29.5 \mathrm{~b}$ & $3.6 \mathrm{~b}$ \\
\hline SP813804 & $16.5 \mathrm{c}$ & $56.4 \mathrm{a}$ & $6.6 \mathrm{~b}$ \\
\hline SP701143 & $45.6 \mathrm{~b}$ & $41.2 \mathrm{~b}$ & $16.5 \mathrm{~b}$ \\
\hline SP791011 & $8.2 \mathrm{c}$ & $41.2 \mathrm{~b}$ & $24.7 \mathrm{~b}$ \\
\hline RB921003 & $44.3 \mathrm{~b}$ & $22.0 \mathrm{c}$ & $44.0 \mathrm{a}$ \\
\hline SP813250 & $59.6 \mathrm{~b}$ & $6.6 \mathrm{c}$ & $6.6 \mathrm{~b}$ \\
\hline RB83160 & $28.4 \mathrm{c}$ & $37.8 \mathrm{~b}$ & $23.5 \mathrm{~b}$ \\
\hline CB45-3 & $49.8 \mathrm{~b}$ & $44.0 \mathrm{~b}$ & $38.5 \mathrm{a}$ \\
\hline RB863129 & $59.7 \mathrm{~b}$ & $16.5 \mathrm{c}$ & $23.2 \mathrm{~b}$ \\
\hline SP841431 & $33.0 \mathrm{c}$ & $6.6 \mathrm{c}$ & $46.4 \mathrm{a}$ \\
\hline VAT90-61 & $29.4 \mathrm{c}$ & $7.3 \mathrm{c}$ & $18.3 \mathrm{~b}$ \\
\hline SP784764 & $46.4 \mathrm{~b}$ & $13.2 \mathrm{c}$ & $13.2 \mathrm{~b}$ \\
\hline SP854594 & $79.9 \mathrm{a}$ & $9.9 \mathrm{c}$ & $39.7 \mathrm{a}$ \\
\hline RB845210 & $83.3 \mathrm{a}$ & $8.2 \mathrm{c}$ & $50.0 \mathrm{a}$ \\
\hline VAT90-186 & $66.5 \mathrm{a}$ & $11.0 \mathrm{c}$ & $38.8 \mathrm{a}$ \\
\hline VAT90-212 & $73.2 \mathrm{a}$ & $6.6 \mathrm{c}$ & $36.4 \mathrm{a}$ \\
\hline SP716949 & $76.6 \mathrm{a}$ & $9.9 \mathrm{c}$ & $63.3 \mathrm{~b}$ \\
\hline RB99395 & $29.6 \mathrm{c}$ & $12.3 \mathrm{c}$ & \\
\hline
\end{tabular}

* Averages followed by the same letter belong to the same group, using the Scott-Knott Test at the 5\% probability level.

Table 2 Average relative DNA content (pg) of the sugarcane varieties verified over consecutive subcultures.

\begin{tabular}{|c|c|c|c|c|c|c|c|c|c|c|}
\hline & Variety & & & & & & & & & \\
\hline $\begin{array}{l}\mathrm{N}^{\circ} \text {. } \\
\text { Subcultures }\end{array}$ & RB83160 & VAT90186 & VAT90212 & $\begin{array}{l}\text { VAT90- } \\
61\end{array}$ & SP701143 & RB863129 & SP854594 & SP784764 & RB845210 & SP716949 \\
\hline $2^{\circ}$ & $\begin{array}{l}12.4904 \\
a\end{array}$ & $12.3874 \mathrm{a}$ & $12.5700 \mathrm{a}$ & $\begin{array}{l}12.3613 \\
b\end{array}$ & $12.3511 \mathrm{a}$ & $12.2605 \mathrm{a}$ & $12.3848 \mathrm{a}$ & 12.6137 a & $12.7171 \mathrm{a}$ & $12.7889 a$ \\
\hline $4^{\circ}$ & $\begin{array}{l}12.4528 \\
a\end{array}$ & $12.1324 \mathrm{a}$ & $12.6606 \mathrm{a}$ & $\begin{array}{l}12.5385 \\
a b\end{array}$ & $12.3980 \mathrm{a}$ & $12.3104 \mathrm{a}$ & $12.4279 \mathrm{a}$ & $12.6131 \mathrm{a}$ & $12.7029 \mathrm{a}$ & $12.9319 a$ \\
\hline $6^{\circ}$ & $\begin{array}{l}12.6707 \\
a\end{array}$ & $12.4170 \mathrm{a}$ & $12.4829 \mathrm{a}$ & $\begin{array}{l}12.7256 \\
a b\end{array}$ & $12.5341 \mathrm{a}$ & 11.8797 b & $12.3752 \mathrm{a}$ & $\begin{array}{l}12.4103 \\
a b\end{array}$ & $12.7583 \mathrm{a}$ & $12.8185 a$ \\
\hline $8^{\circ}$ & $\begin{array}{l}12.5127 \\
a\end{array}$ & 12.4583 a & $12.5730 \mathrm{a}$ & $\begin{array}{l}12.7602 \\
a\end{array}$ & $12.2788 \mathrm{a}$ & 11.7498 b & $12.4327 \mathrm{a}$ & $12.2249 \mathrm{~b}$ & $12.8551 \mathrm{a}$ & $12.9703 \mathrm{a}$ \\
\hline
\end{tabular}

* Averages followed by the same letter, belong to the same group, using the Scott-Knott Test at the 5\% probability level.

Table 3 Response of sugarcane sprouts multiplied in liquid medium (LM) and semi-solid medium (SSM) to the process of in vitro rhyzogenesis. 


\begin{tabular}{|lllllll|}
\hline \multicolumn{4}{|l}{ Rooting (\%) } & \multicolumn{2}{l}{ Root number } & \multicolumn{2}{l}{ Shoot number } \\
\hline Variety & LM & SSM & LM & SSM & LM & SSM \\
\hline RB 845210 & $60 \mathrm{bB}$ & $100 \mathrm{aA}$ & $27.0 \mathrm{bA}$ & $22.4 \mathrm{bA}$ & $3.9 \mathrm{aB}$ & $7.3 \mathrm{aA}$ \\
\hline SP 784764 & $90 \mathrm{aA}$ & $80 \mathrm{aA}$ & $36.0 \mathrm{bA}$ & $20.0 \mathrm{bB}$ & $3.7 \mathrm{aA}$ & $3.3 \mathrm{bA}$ \\
\hline SP 701143 & $90 \mathrm{aA}$ & $90 \mathrm{aA}$ & $45.0 \mathrm{aA}$ & $28.0 \mathrm{bB}$ & $3.6 \mathrm{aA}$ & $5.4 \mathrm{aA}$ \\
\hline RB 83160 & $100 \mathrm{aA}$ & $80 \mathrm{aA}$ & $54.0 \mathrm{aA}$ & $34.0 \mathrm{aB}$ & $3.2 \mathrm{aA}$ & $2.8 \mathrm{bA}$ \\
\hline VAT 90-212 & $100 \mathrm{aA}$ & $90 \mathrm{aA}$ & $25.8 \mathrm{bA}$ & $26.2 \mathrm{bA}$ & $3.8 \mathrm{aA}$ & $4.9 \mathrm{aA}$ \\
\hline SP 716949 & $100 \mathrm{aA}$ & $90 \mathrm{aA}$ & $41.0 \mathrm{aA}$ & $36.0 \mathrm{aA}$ & $2.5 \mathrm{aA}$ & $3.9 \mathrm{bA}$ \\
\hline RB 863129 & - & $100 \mathrm{aA}$ & - & $19.1 \mathrm{bA}$ & - & $2.7 \mathrm{bA}$ \\
\hline VAT 90-61 & - & $100 \mathrm{aA}$ & - & $41.0 \mathrm{aA}$ & - & $4.2 \mathrm{bA}$ \\
\hline SP 854594 & - & $100 \mathrm{aA}$ & - & $23.8 \mathrm{bA}$ & - & $6.0 \mathrm{aA}$ \\
\hline VAT 90-186 & - & $100 \mathrm{aA}$ & - & $41.0 \mathrm{aA}$ & - & $6.8 \mathrm{aA}$ \\
\hline
\end{tabular}

* Averages followed by the same lower-case letter in the column do not differ statistically from each other by the Scott-Knott test at the $5 \%$ probability level. Different capital letters within each variable differ from each other by the F-test.

\section{Figures}

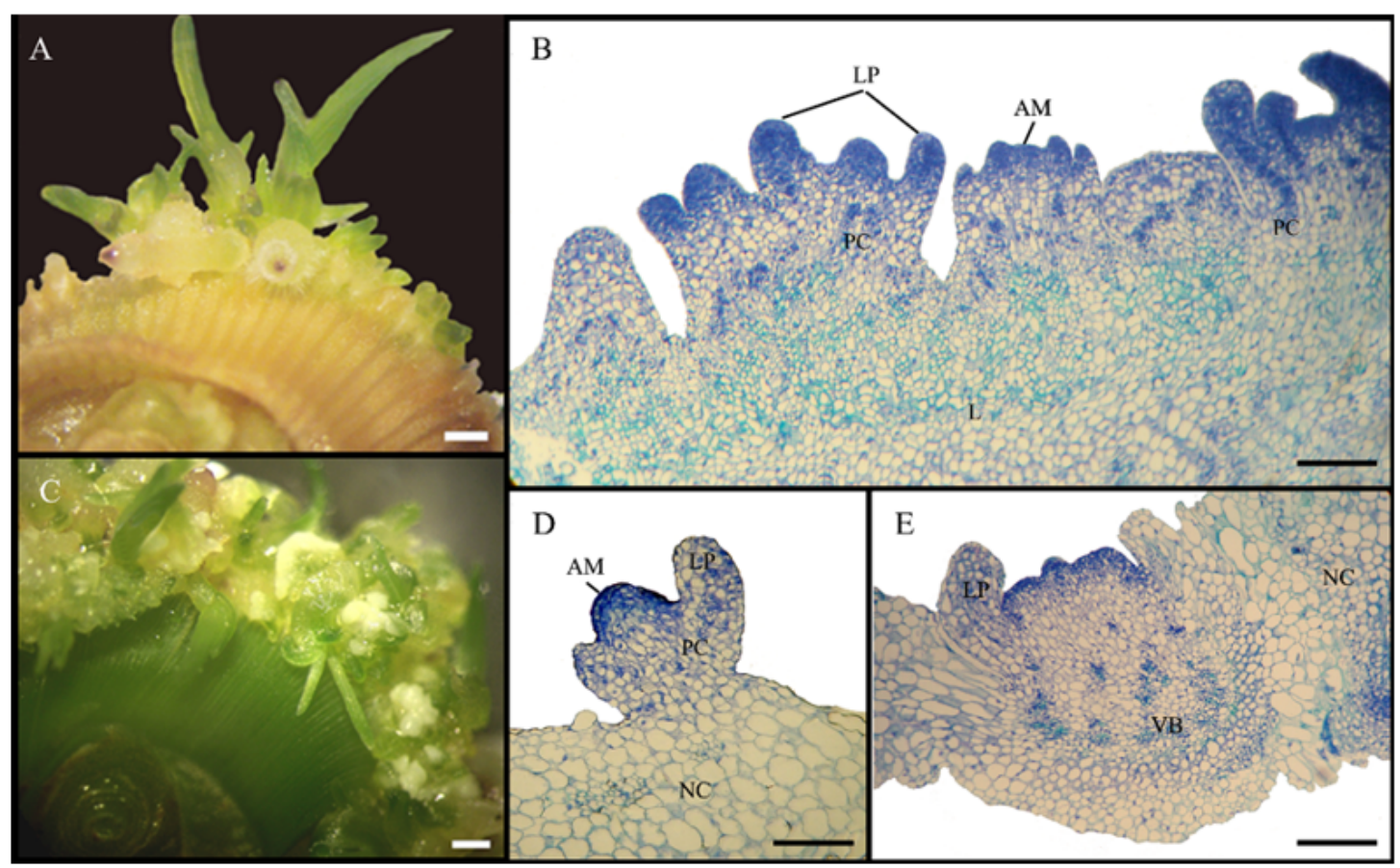

\section{Figure 1}

In vitro organogenesis of Saccharum sp. from adult plant stem tips. A: Direct regeneration after 30 days of cultivation observed in the RB845210 variety; B: Histological analysis showing adventitious buds at different stages of development, formed directly from the leaf explant; C: Aspect of indirect regeneration with callus formation in sections of explants in the VAT90-212 variety; D: Adventitous bud, originating from nodular callus, in a more advanced stage of development, presenting primordial leaves and vascular bundles. E: Development of shoots in induction medium containing NAA + KIN after 40 days of cultivation. AM: apical meristem of the stem; LP: leaf primordia; PC: procambium; L: source leaf; NC: nodular callus; VB: vascular bundles (Bars $A, C$ and $E=1 \mathrm{~mm} ; B$ and $D=50 \mu \mathrm{m})$. 
A

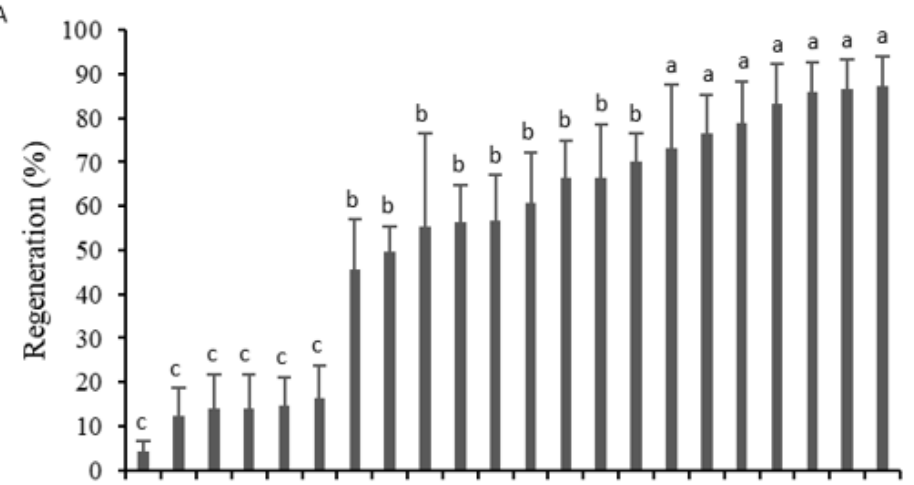

B

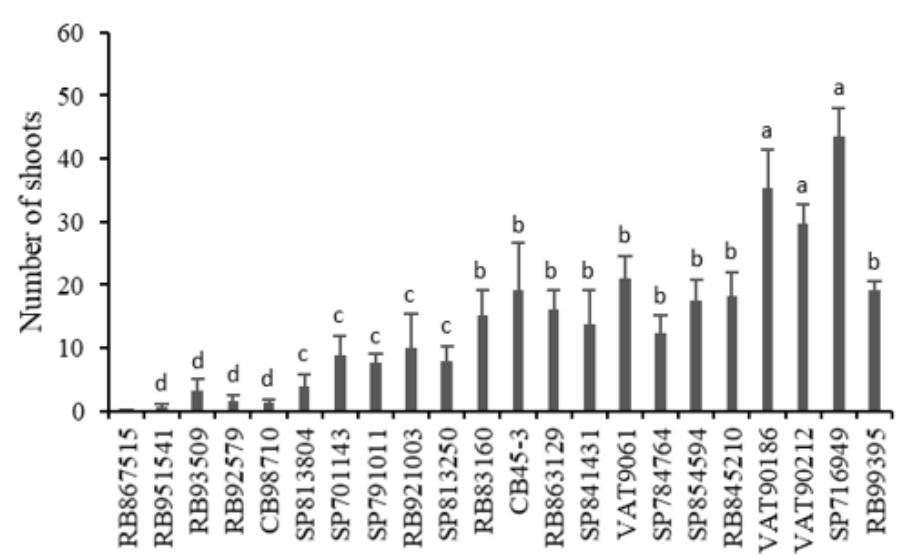

Figure 2

Comparison of Brazilian varieties of sugarcane regarding the percentage of regeneration (A) and average formation of shoots per repetition (B), after 40 days of cultivation in MS culture medium supplemented with $5.0 \mathrm{mg} \mathrm{L-} 1$ of NAA and $0.5 \mathrm{mg}$ L- 1 of KIN. Varieties with the same letter do not differ by the Scott-Knott test at the 5\% probability level. 

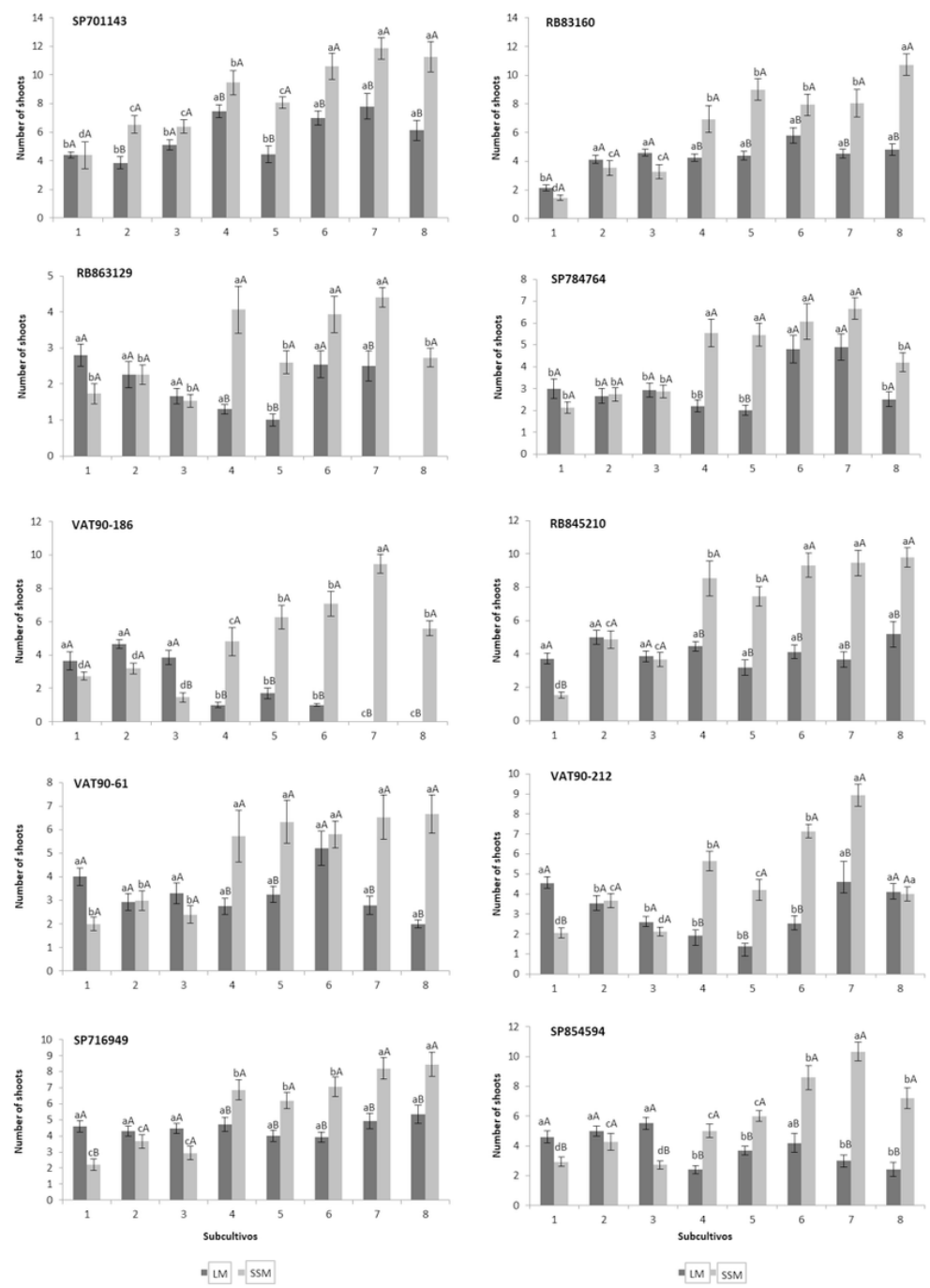

\section{Figure 3}

Multiplication rates in liquid (LM) and semi-solid (SSM) mediums of the ten Brazilian sugarcane varieties in eight consecutive subcultures. * Lower case letters compare the formation of shoots within each medium and upper-case letter compare between the mediums, indicating that averages followed by the same letter belong to the same group by the Scott-Knott Test at the $5 \%$ probability level. 


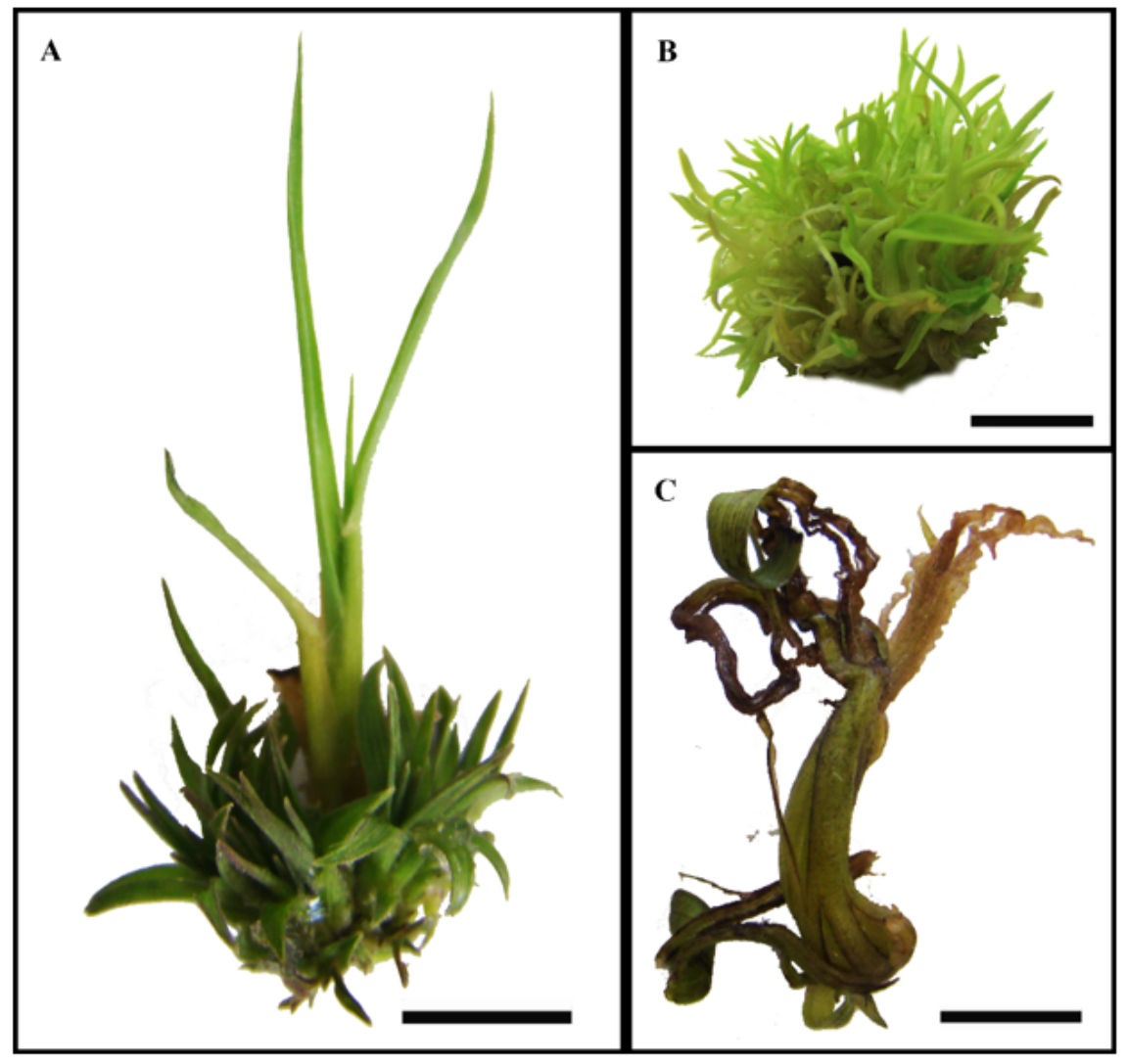

Figure 4

Morphological variations observed in different varieties of sugarcane after consecutive subcultures in semi-solid medium. Highlight for the rosette type arrangement, with thickening of shoots in the basal region $(\mathrm{A})$, formation of green masses $(\mathrm{B})$ and the aspect of abnormality $(\mathrm{C})(\mathrm{Bars}=1 \mathrm{~cm})$.

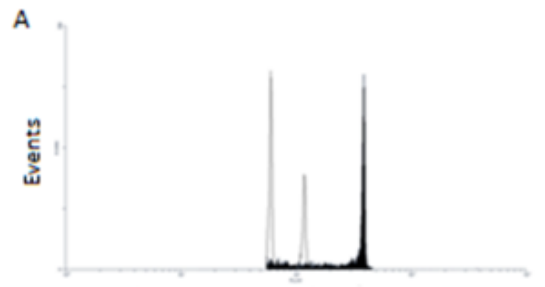

Fluorescence intensity

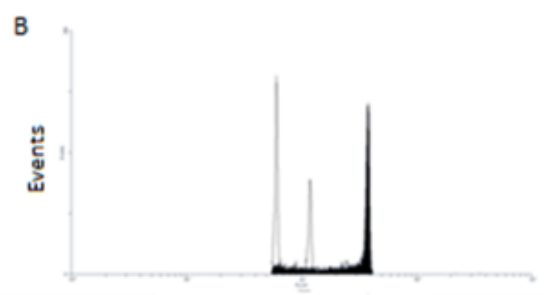

Fluorescence intensity

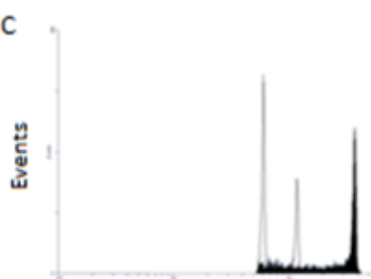

Fluorescence intensity

Figure 5

Histograms related to flow cytometry analysis of the amount of sugarcane DNA obtained using the Marie buffer. The first peak corresponds to the tomato pattern and the second peak corresponds to sugarcane. A: SP716949 variety; B: VAT90-186 variety; C: RB863129 variety. 


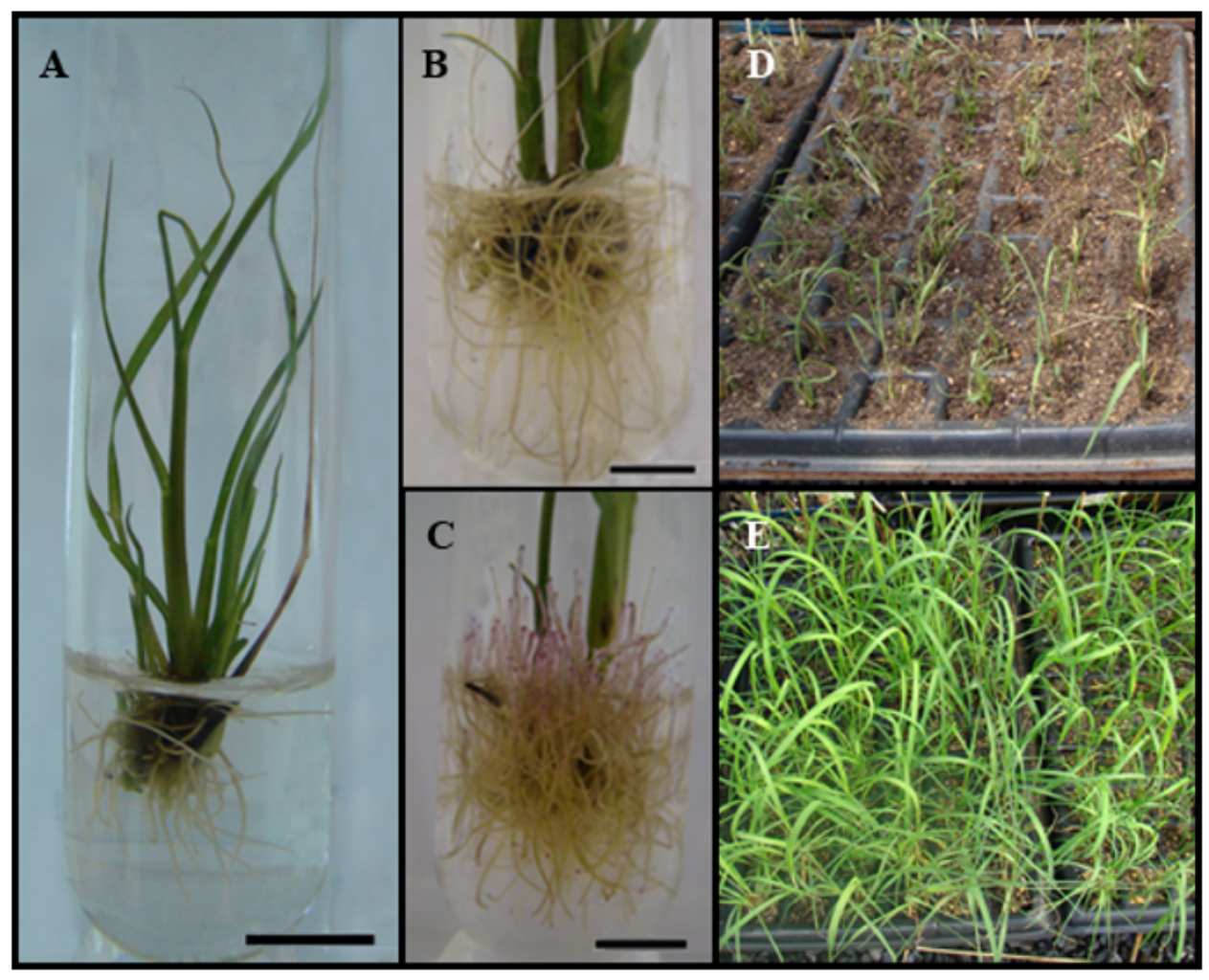

\section{Figure 6}

Visual aspect of sugarcane sprouts after 40 days in rooting medium and during the acclimatization period. A: Overview of the aerial part and developed root system; B: Proliferation of roots by sprouting from the semi-solid medium; C: Proliferation of roots by sprouting from the liquid medium; D: Day of transfer of sprouts to substrate of vegetal soil and sand; E: Sprouts growth and development 21 days after transplantation $(B a r s ~ A-C=1 \mathrm{~cm})$. 